\title{
FUNDAMENTAÇÃO PRAGMÁTICO-TRANSCENDENTAL DA VALIDADE UNIVERSAL DOS DIREITOS HUMANOS
}

\author{
Victor de Resende Mota ${ }^{1}$ \\ Aluno do curso de Direito da UFC, orientado pelo prof. dr. Regenaldo \\ Rodrigues da Costa. Bolsista de Iniciação Científica do CNPq. Membro \\ do Grupo de Pesquisa de Filosofia dos Direitos Humanos (UFC/CNPq). \\ victormota28@hotmail.com
}

Sumário: Introdução. 1. Análise pragmático-transcendental dos atos da fala. 2. O argumento pragmático-transcendental de fundamentação última das normas morais do discurso. 3. A validade universal dos direitos humanos e a necessidade de um discurso normativo intercultural. Conclusão. Referências.

Resumo: Apesar de sua enorme importância jurídico-filosófica, a ideia de direitos humanos ainda enfrenta muitos desafios no atual panorama mundial, não apenas referentes à efetivação, mas principalmente à própria justificação perante toda a comunidade internacional. Uma das principais críticas dirigidas aos direitos humanos contesta a sua pretensão de validade universal, afirmando que tais direitos não passam de uma forma velada de imposição da cultura e dos valores ocidentais sobre os outros povos. Contra essa postura relativista, o presente trabalho busca desenvolver o argumento pragmático-transcendental de Karl-Otto Apel, por meio do qual se pretende revelar as normas morais pressupostas em toda argumentação com sentido, a fim de fundamentar racionalmente a possibilidade de universalização dos direitos humanos e de um discurso normativo intercultural que possa harmonizar esses direitos com as peculiaridades das diversas culturas sem sacrificar seu poder crítico e emancipador.

Palavras-chave: Direitos Humanos. Universalismo. Pragmática transcendental.

Bacharelando do $5^{\circ}$ Semestre da Faculdade de Direito da Universidade Federal do Ceará (UFC). Bolsista de Iniciação Científica do CNPq. Membro do Grupo de Pesquisa de Filosofia dos Direitos Humanos (UFC/CNPq). E- mail: <victormota28@hotmail.com> 


\section{INTRODUÇÃO}

Principalmente após a Declaração Universal da ONU (1948), os direitos humanos passaram a obter força normativa cada vez maior, não apenas no cenário internacional, com a celebração de vários acordos entre grande número de países (como o Pacto Internacional dos Direitos Civis e Políticos, com 154 Estados-partes, e o Pacto dos Direitos Econômicos, Sociais e Culturais com 151 Estados-partes), mas também no ordenamento jurídico interno de diversos Estados, graças à influência exercida na elaboração de suas Constituições e na formulação de seus catálogos de direitos fundamentais, além da incorporação dos tratados e convenções internacionais ao direito nacional. "A partir da Declaração de 1948, começa a se desenvolver o Direito Internacional dos Direitos Humanos, mediante a adoção de inúmeros instrumentos internacionais de proteção" (PIOVESAN, 2007, p.13).

Com o progressivo desenvolvimento e fortalecimento do sistema normativo global e dos sistemas regionais de proteção dos direitos humanos, grandes juristas de diversos países passaram a ter a preocupação cada vez maior de destacar e reforçar a indivisibilidade e, sobretudo, a universalidade desses direitos, haja vista que o próprio conceito de direitos humanos pressupõe que a sua titularidade se estenda a todas pessoas tão somente pela sua humanidade.

O que normalmente se percebe, entretanto, é que essa universalidade tão propalada pelos defensores dos direitos humanos não é adequadamente justificada, sendo fundada na mera crença em sua validade, em um suposto consenso vigente entre os países ou simplesmente no fato de assim estar estabelecido nos tratados internacionais. A título ilustrativo dessa tendência, pode-se citar Flávia Piovesan (2007, p.13): "Universalidade [...] clama pela extensão universal dos direitos humanos, sob a crença de que a condição de pessoa é o requisito único para a titularidade de direitos" (Grifo nosso). Também Cançado Trindade (2003, p.37) afirma no mesmo sentido: "Subjacente a esta evolução [dos direitos humanos] encontra-se a crença, já sedimentada na consciência coletiva, na dignidade inerente à pessoa humana" (Grifo nosso). Ainda segundo o ilustre jurista, "a universalidade dos direitos humanos [...] vem ser sustentada, em termos inequívocos, nas duas Conferências Mundiais de Direitos Humanos (Teerã, 1968, e Viena, 1993)." Desse modo, ao invés de os documentos internacionais de direitos humanos se basearem na validade universal de tais direitos, por vezes, é o contrário que se defende.

As formas usuais de justificação da validade universal dos direitos humanos, por serem dogmáticas e se basearem principalmente em elementos fáticos, como a crença, os tratados internacionais ou os consensos vigentes, acabam fragilizando a própria capacidade normativa e a possibilidade de aceitação desses 
direitos, ensejando diversas críticas principalmente por parte dos relativistas, que afirmam serem tais direitos apenas uma forma velada de imposição dos valores ocidentais sobre as demais culturas e cosmovisões. "Na crítica dos relativistas, os universalistas invocam a visão hegemônica da cultura eurocêntrica ocidental, na prática de um canibalismo cultural" (PIOVESAN, 2007, p.17).

Diante desse quadro, o presente trabalho visa empreender uma tentativa de fundamentação racional da validade universal dos direitos humanos e da possibilidade de um discurso normativo intercultural em que tais direitos possam ser discutidos e harmonizados com peculiaridades culturais diversas sem perder sua força crítica e normativa. Para tanto, apresentar-se-á, em linhas gerais e em seus traços fundamentais, a argumentação pragmático-transcendental de Karl-Otto Apel, que almeja revelar as condições normativas necessariamente pressupostas em toda argumentação com sentido, buscando chegar às normas morais fundamentais e possibilitadoras do discurso sério, isto é, pretende-se atingir as normas de fundamentação última da ética e do discurso prático, as quais não podem ser negadas pelos relativistas ou céticos sem que estes caiam em contradição com seus próprios pressupostos.

A metodologia adotada é de caráter bibliográfico, tendo sido utilizadas principalmente obras de Karl-Otto Apel, por ter ele desenvolvido o argumento pragmático-transcendental, e de Jürgen Habermas, pelas importantes contribuições ao esclarecimento e à formulação desse argumento e de conceitos que lhe são fundamentais.

\section{Análise Pragmático-Transcendental dos Atos da Fala}

A proposta apeliana de fundamentação última da ética tem como um dos principais pontos de partida teóricos a teoria dos atos da fala, desenvolvida principalmente por John Austin e John Searle e modificada por Jürgen Habermas em sua pragmática formal.

Uma das principais inovações da teoria dos atos da fala é a de que, ao se dizer algo, também se faz alguma coisa dentro do mundo social, de relações interpessoais normativamente reguladas, ou seja, falar consiste em uma série de ações com repercussões sociais em certo grupo linguístico. Assim, atos, como ordenar, prometer, pedir, casar e batizar, por exemplo, desempenham-se linguisticamente, mas seus elementos centrais não residem no que é dito, mas no que é feito por meio deles e nos vínculos humanos que permitem estabelecer e conservar.

Enquanto a semântica formal da filosofia analítica examina as proposições independentemente do contexto em que foram proferidas e das intenções dos falantes, orientando suas investigações apenas em função das 
condições de verdade dos enunciados linguísticos e destacando apenas a função representativa da linguagem, a teoria dos atos da fala vai além dessa limitação metodológica e põe em relevo a dimensão pragmática da fala humana, destacando a função socialmente vinculante e comunicativa da linguagem, sem abstrair das intenções e dos pressupostos comunicativos dos interlocutores e sem negligenciar as regras subjacentes ao uso das expressões linguísticas nas situações de fala.

Para a fundamentação última da ética, importa, sobretudo, destacar duas contribuições teóricas baseadas na teoria dos atos da fala. A primeira delas é a tematização da dupla estrutura performativo-proposicional do discurso humano. $\mathrm{O}$ aspecto performativo ou ilocucionário (força ilocucionária) de uma oração consiste no que é feito pelo falante com a expressão linguística e no modo pelo qual o conteúdo dessa expressão se apresenta ao ouvinte, ou seja, é o seu caráter de afirmação, ordem, pedido, pergunta, promessa, dentre outras tipologias. A parte proposicional ou locucionária (conteúdo proposicional), por sua vez, é o que é dito pela oração, isto é, trata-se do que é afirmado (predicação) acerca de algo (referência).

Uma importante consequencia dessa divisão é a capacidade reflexiva das linguagens naturais por meio da qual os falantes competentes são capazes de refletir criticamente sobre a linguagem por meio dela mesma. Sobre isso fala Habermas (2002, p.67): “A esta dupla estrutura do discurso está ligada uma característica básica da linguagem: a sua inerente reflexividade. As possibilidades [....] de mencionar [....] o discurso apenas tornam explícita uma autorreferência que já se encontra contida em todos os atos de fala".

Outro tópico de grande relevância para a fundamentação última é a formulação habermasiana das pretensões de validade vinculadas ao aspecto performativo dos atos da fala. Segundo Habermas, quando se age comunicativamente, isto é, usando a linguagem para o entendimento mútuo, atrelam-se quatro pretensões de validade aos atos de fala proferidos: sentido (inteligibilidade), verdade, sinceridade ou seriedade e correção normativa.

A pretensão de sentido refere-se à capacidade de o enunciado linguístico ser adequadamente compreendido pelo ouvinte e é condição das demais pretensões. A pretensão de verdade tematiza o conteúdo proposicional da oração proferida e sua relação com os fatos do mundo objetivo. A pretensão de correção versa sobre a adequação do proferimento ao contexto normativo subjacente à situação da fala, isto é, à sua adequação a valores e normas pressupostas pelos interagentes ou, em discursos práticos, tematiza a própria validade intersubjetiva dessas normas. Por fim, a pretensão de sinceridade diz respeito à correspondência entre o que é expresso linguisticamente pelo falante e seus reais estados psicológicos.

De acordo com a pretensão de validade destacada e com a função predominante da linguagem envolvida em um proferimento, os atos de fala foram classificados pelo filósofo em três classes: os constatativos (como é o caso de 
afirmações, classificações e descrições), em que se sobressaem a pretensão de verdade e a função cognitiva da linguagem (representação de fatos no mundo objetivo); os regulativos (como é o caso de ordens, pedidos e promessas), em que se ressaltam a pretensão de correção e a função interativa da linguagem (estabelecimento de uma relação interpessoal legítima no mundo social); os expressivos (como é o caso de confissões, desejos, declarações de intenção), em que se destacam a pretensão de sinceridade e a função expressiva da linguagem (revelação de conteúdos psicológicos e experiências íntimas do mundo subjetivo). Conclui Habermas (2002, p.67): “Através dos seus atos ilocutórios [atos da fala], tanto o falante como o ouvinte apresentam pretensões de validade, cujo reconhecimento exigem".

Desse modo, ao proferir atos da fala (atos ilocucionários), o falante atrela-lhes simultaneamente as quatro pretensões de validade supracitadas, porém sempre destacando uma delas de acordo com seus propósitos comunicativos. Com tal teoria, ultrapassa-se a abordagem estritamente semântica da filosofia analítica, sistematiza-se e aprimora-se a ideia básica de Austin de que os atos da fala possuem diversas condições de validade, isto é, de aceitabilidade e reconhecimento intersubjetivo, que não se limitam às condições de verdade, como queria a semântica formal: para ser válido, por tanto, um ato da fala precisa ser inteligível, sincero ou sério, verdadeiro e correto ou adequado.

Consistindo em reivindicações de que as condições de validade dos atos de fala proferidos são satisfeitas, as pretensões de validade apresentadas implicitamente pelo falante acarretam-lhe uma obrigação de fundamentação: a de fornecer fundamentos para justificar a verdade dos atos de fala constatativos e a de fornecer a justificativa que o autoriza a realizar o proferimento no caso dos atos de fala regulativos. Tais pretensões de validade são ainda discursivamente criticáveis e problematizáveis, devendo, quando necessário, ser discutidas no discurso argumentativo em busca de um consenso. Concluímos, com Regenaldo da Costa (2002, p. 254), que "todas as nossas pretensões à validade, como, por exemplo, a pretensão à verdade e à correção normativa, são constituídas linguisticamente e só linguisticamente (isto é discursivo-argumentativamente) podem ter sua validade atestada".

\section{O Argumento Pragmático-Transcendental de Fundamentação Última das Normas Morais do Discurso}

\subsection{Estrutura Lógica doArgumento Pragmático-transcendental}

Um argumento recebe a qualificação de transcendental, grosso modo, se, a partir de algo reconhecidamente aceito como indubitável, conclui-se 
a existência de outra coisa que seja sua condição necessária de possibilidade e validade. Trata-se, em sua estrutura lógica elementar, de um modus ponens: "se A é, então B é; como A é necessariamente; então B é necessariamente", sendo A um objeto cuja existência é reconhecida como inegável e sendo B a condição necessária de sua possibilidade e validade, cuja existência necessária é provada a partir da constatação de que A sempre se verifica. Robert Alexy (2010, p. 105 -106) dá a seguinte definição:

Aqui, devem, como "transcendentais", ser designados argumentos que se compõem, pelo menos, de duas premissas com a estrutura seguinte: a primeira premissa identifica o ponto de partida do argumento, que consiste de coisas como percepções, ideias ou atuações linguísticas e afirma, desse ponto de partida, que ele, em algum sentido, é necessário. A segunda premissa diz, a seguir, que algumas categorias ou regras são necessárias se o objeto escolhido como ponto de partida deve ser possível. A conclusão diz, finalmente, que essas categorias ou regras devem valer necessariamente.

Um argumento pragmático-transcendental, portanto, é aquele que parte da inevitabilidade da argumentação e da comunicação humanas para provar a existência de seus pressupostos necessários.

\subsection{A neCESSIDAde DA ARGUMENTAÇÃo}

Em primeiro lugar, portanto, deve-se justificar em que sentido a argumentação deve ser entendida como "necessária". Em seu cotidiano no mundo da vida, os indivíduos ao agirem comunicativamente, isto é, visando à compreensão e ao entendimento mútuos, levantam implicitamente pretensões de validade que devem ser aceitas pelo interlocutor. Quando, porém, tais pretensões são problematizadas, passa-se da esfera da ação para a do discurso argumentativo, em que essas pretensões serão analisadas e discutidas.

Em nenhuma forma de vida, independentemente dos valores ou da cosmovisão preponde rante, há como fugir completamente da ação linguística orientada para o entendimento, por meio da qual os indivíduos aprendem, ensinam, trocam experiências, colaboram uns com os outros e planejam ações conjuntas. É também por meio da ação comunicativa que se desenvolve o próprio processo de formação e afirmação da identidade e de assimilação dos valores e dos costumes da comunidade. Segundo Habermas (2003, p. 125), "um salto prolongado para fora dos contextos do agir orientado para o entendimento mútuo [....] significaria a retirada para o isolamento monádico do agir estratégico - ou para dentro da esquizofrenia ou suicídio. A longo prazo, ele é autodestruidor". Consequentemente, não há como se subtrair totalmente ao discurso argumentativo, que continua e 
aprofunda os pressupostos já presentes do agir comunicativo. Enfatiza o filósofo alemão (2003, p. 123) que "não existe nenhuma forma de vida sociocultural que não esteja pelo menos implicitamente orientada para o prosseguimento do agir comunicativo com meios argumentativos".

Também, na reflexão solitária, o sujeito que delibera consigo mesmo pressupõe uma estrutura linguística pública, cujas regras de argumentação, termos e expressões aprendeu a usar graças a outras pessoas, estando necessariamente inserido, portanto, em uma comunidade discursiva. Além disso, quando faz uma reflexão, delibera para tomar uma decisão e pondera razões e interesses, o indivíduo também levanta implicitamente pretensões de validade que deveriam potencialmente ser sustentadas e aprovadas perante todos os demais, ou consoante fala Perelman, perante o "auditório universal". Com efeito, afirma o ilustre teórico da argumentação (2005, p. 45-46):

O sujeito que delibera é considerado, em geral, uma encarnação do auditório universal. Com efeito, parece que o homem dotado de razão, que procura formar-se uma convicção [...] não pode, crê-se, deixar de ser sincero consigo mesmo e é, mais do que ninguém, capaz de experimentar o valor dos próprios argumentos [...] O acordo consigo mesmo é apenas um caso particular de acordo com os outros.

Desse modo, seja com os outros, seja consigo mesmo, o ser humano, enquanto ser racional, dotado da capacidade de agir, falar e pensar, não pode renunciar à ação linguística orientada ao entendimento e a se guiar por meio de pretensões de validade, que exigem, quando problematizadas e questionadas, o discurso argumentativo sério a fim de que possam ser adequadamente discutidas e de que o consenso possa ser restaurado. Concluímos, pois, com Habermas (2003, p. 123) que "o salto [....] para fora da argumentação e do agir orientado para o entendimento mútuo leva-o [o cético] a um impasse existencial".

\subsection{A Reflexão Pragmático-Transcendental e os Pressupostos NeCESSÁRIOS do Discurso}

É no domínio da argumentação, em que são discutidas as pretensões de validade problematizadas na ação comunicativa, que tem lugar a reflexão pragmático-transcendental sobre as condições normativas pressupostas em todo ato argumentativo dotado de sentido. Como esclarece Manfredo de Oliveira (1993, p.68): “... A pragmática transcendental faz da reflexão transcendental uma reflexão sobre as condições de possibilidade e validade da argumentação sensata".

Tal perquirição transcendental tem como princípio orientador a não autocontradição performativa, que consiste em evitar a contradição do conteúdo 
proposicional de um ato ilocucionário com o conteúdo de um dos pressupostos necessários do seu componente performativo. Esse princípio é a principal ferramenta metodológica para a descoberta das pressuposições universalmente necessárias em toda discussão com sentido, atuando como uma navalha de modo a discernir os fundamentos últimos da argumentação de suas premissas meramente contingentes. Habermas (2003, p. 102) dá a seguinte definição: “... contradição performativa [...] surge quando um ato de fala constatativo ' $\mathrm{Cp}$ ' se baseia em pressuposições não-contingentes cujo conteúdo proposicional contradiz o enunciado asserido " $p$ "”.

A contradição performativa (transcendental-pragmática) deve ser ainda distinguida de outras duas espécies de contradição: a semântica ou proposicional (que se dá entre os conteúdos proposicionais de atos da fala distintos) e a pragmática empírica (que se dá entre o conteúdo proposicional de um ato ilocucionário e as ulteriores ações do falante).

Valendo-se, portanto, do princípio da contradição performativa, a pragmática transcendental busca os fundamentos intranscendíveis da argumentação e, por conseguinte, as suas normas morais possibilitadoras, que constituem a fundamentação última da ética, porquanto não podem ser negadas pelo cético nem pelo relativista sem que estes incorram em autocontradição performativa. Tais proposições fundamentais são discerníveis pelo seguinte critério: não podem ser negadas sem autocontradição performativa e não podem elas mesmas ser fundamentadas sem que haja petição de princípio.

Ao empreender a reflexão transcendental na busca dos pressupostos normativos da argumentação, Apel busca refutar o solipsismo metodológico, postura teórica segundo a qual o sujeito cognoscente pode chegar sozinho a enunciados intersubjetivamente válidos (verdadeiros e corretos), amparado por uma relação direta e imediata com os dados sensoriais ou com as ideias ou intuições da razão e do intelecto (relação sujeito-objeto).

Para refutar essa perspectiva epistemológica do pensador solitário, Apel (2001, p. 46) tenta mostrar que "cada pensamento ou cognição de algo enquanto algo [...] precisa já pressupor a mediação de seu significado intencional por meio da linguagem pública" (tradução nossa), isto é, a reflexão e o próprio pensamento são constituídos de termos e expressões que se aprendem no seio de uma comunidade de falantes e sua estrutura se baseia na argumentação pública, que também é assimilada de tal comunidade.

No uso das palavras e frases, portanto, já se pressupõe um acordo intersubjetivo sobre o seu sentido, isto é, o reconhecimento das regras da linguagem e da comunicação no âmbito de uma relação sujeito-sujeito, a qual ocorre no seio de uma comunidade linguística historicamente determinada. Segundo Apel (2000, p. 407), "o acordo mútuo intersubjetivo enquanto mediatização da tradição é, ele 
sim, a condição de possibilidade e de validade transcendental-hermenêutica de toda cognição objetivamente orientada". A própria “objetividade", portanto, passa a ser compreendida como validade intersubjetiva alcançada em um consenso numa comunidade discursiva. Aduz ainda o filósofo (2000, p. 321) que "não é possível pensar um sujeito, em princípio solitário e autárquico [...] por causa da dependência da linguagem de todo pensar intersubjetivamente válido de algo enquanto algo".

Apesar de reconhecer que a consciência individual constitui uma mediação importante entre o sujeito e o mundo, sendo também um pressuposto necessário de seu pensar e agir, a pragmática transcendental vai além da filosofia moderna da consciência para assinalar a importância fundamental da mediação da linguagem na formação de nossos pensamentos, na interpretação e na pré-compreensão do mundo, além de destacar que mesmo aquele que pensa isoladamente não o faz sozinho, mas com os outros, porquanto sempre pressupõe uma comunidade linguística, cultural e histórica da qual faz parte e na qual construiu sua personalidade mediante um processo de aprendizado e socialização. Concluímos, pois, com Apel (2001, p. 46): "Mediante reflexão transcendental podemos descobrir que, juntamente com o pensar sério enquanto argumentar, nós já sempre devemos pressupor a existência e a cooperação de parceiros discursivos" (tradução nossa).

Desse modo, por meio da reflexão sobre as condições de possibilidade e da validade da argumentação, chega-se ao a priori da comunidade de comunicação, pressuposta sempre em cada ato argumentativo de forma dupla: quem argumenta pressupõe uma comunidade real de comunicação, da qual efetivamente faz parte, e antecipa contrafaticamente uma comunidade ideal de comunicação, potencialmente ilimitada, capaz de compreender seus argumentos e julgar-lhes a validade de modo definitivo.

Com efeito, ao argumentar, pressupõe-se a pertença à determinada comunidade cultural e histórica, na qual se aprendeu o uso do idioma e se forjou a personalidade e da qual se assimilaram valores e tradições. O homem, enquanto ser social e político, de fato, constroi sua própria identidade a partir da visão que os outros dele fazem e a partir dos papéis que desempenha em sua comunidade linguística. Trata-se da comunidade real de comunicação, cujo reconhecimento já demonstra a impossibilidade do solipsismo.

Além de uma comunidade histórica, no ato de argumentação, pressupõe-se também uma comunidade ideal e virtualmente ilimitada de comunicação. Ao apresentarem suas pretensões de validade em um discurso, os falantes necessariamente pressupõem que tais pretensões poderiam ser argumentativamente defendidas perante qualquer um em qualquer tempo ou lugar, ou seja, as genuínas pretensões de validade (sentido, sinceridade, verdade, correção) são universais no sentido de que devem ser reconhecidas não apenas 
em um auditório particular com determinadas características socioculturais, mas perante um auditório universal, isto é, toda humanidade, independemente do específico contexto histórico ou cultural. Quanto a isso esclarece Habermas (2004, p. 254): "O que consideramos verdadeiro deve ser defendido com razões convincentes não só em outro contexto, mas também em todos os contextos possíveis, ou seja, a todo momento e contra quem quer que seja."

Tal comunidade ideal apresenta determinadas normas de cunho moral cuja observância é condição necessária da possibilidade e da validade de uma argumentação séria. Apesar de essas condições normativas muitas vezes não serem efetivamente cumpridas, são sempre pressupostas por qualquer falante que pretenda engajar-se num genuíno discurso argumentativo sob pena de incorrer em autocontradição performativa caso se rejeitem tais normas. A comunidade ideal de comunicação é, pois, antecipada contrafaticamente (contra os fatos), porque, muitas vezes, não se verifica na comunidade real, mas é sempre pressuposta independentemente da vontade, dos interesses ou das expectativas dos envolvidos, porquanto as normas pragmático-transcendentais não dependem das inclinações dos falantes, mas das pressuposições inevitáveis feitas pelos que argumentam e das próprias regras da argumentação e da linguagem.

Segundo Apel (2001, p. 47-49), na antecipação da comunidade ideal, pressupõe-se o postulado do consenso, segundo o qual os participantes do discurso querem e se disponibilizam a resolver todas as controvérsias só mediante argumentos, sem recurso à violência, ameaça, fraude, persuasão, suborno e outras formas de negociação estratégica. Todos concentram suas energias, portanto, para atingir o consenso racional em que deve prevalecer só o melhor argumento. Além disso, o filósofo também defende que duas normas fundamentais são sempre pressupostas no discurso: o reconhecimento de direitos iguais a todos por cada participante da argumentação e a responsabilidade solidária entre eles pela identificação e solução dos problemas do mundo da vida no domínio argumentativo. Fundamentalmente, Habermas (2004, p. 254) concorda com a antecipação dessas normas ideais:

Quem sempre entra numa discussão com a séria intenção de se convencer de algo na conversa [...] deve supor [...] de maneira contrafactual uma situação de conversação que preenche condições improváveis: publicidade e inclusão, participação com direitos iguais para todos, imunização contra coerções externas e internas, como também a orientação dos participantes pelo entendimento mútuo.

A partir dessas normas pragmático-transcendentais antecipadas contrafaticamente, afirma Apel, juntamente com Habermas, chega-se ao princípio moral fundamental, que este último pensador cunhou de Princípio da Universalização $(\mathrm{U})$ : 
Qualquer norma válida deverá satisfazer a condição de que as consequências e os efeitos secundários que resultem previsivelmente da sua observância universal para a satisfação dos interesses de cada indivíduo, possam ser aceitas livremente por todos os afetados (HABERMAS, 1999, p.34).

Sintetizando, pois, o argumento pragmático-transcendental de fundamentação da ética, pode-se dizer que a argumentação é uma atividade indispensável para o ser humano, da qual ele não pode abdicar sob pena de exclusão voluntária da sociedade e de perda da própria capacidade de autocompreensão e que tal atividade argumentativa pressupõe necessariamente certas condições normativas que não se podem negar sob pena de se cair em contradição consigo mesmo e com as próprias pressuposições.

\section{A Validade Universal dos Direitos Humanos e a Necessidade de um Discurso Normativo InTercultural}

Das normas pragmático-transcendentais (inclusão de todos aqueles que podem tomar parte no discurso, igualdade de direitos e igual consideração das necessidades e interesses de cada um, liberdade, ausência de coação externa e interna, responsabilidade solidária na identificação e solução dos problemas práticos) chega-se ao princípio da universalização, que é, por sua vez, uma norma procedimental que atua como parâmetro de validade de normas concretas de ação e que é fundamental como guia e diretriz na realização de um discurso normativo intercultural.

Para que não se trate de um processo arbitrário e unilateral, a validade universal dos direitos humanos, isto é, seu reconhecimento e acolhimento intersubjetivos pela comunidade internacional se devem dar por meio de um diálogo normativo intercultural, abrindo-se espaço para múltiplas possibilidades de leitura e de interpretação de tais direitos de modo a harmonizá-los a visões de culturas diversas. Sobre isso, afirma o pensador alemão Heiner Bielefeldt (2000, p. 32): "Em função da universalidade dos direitos humanos, o debate intercultural é inevitável."

Esse diálogo, entretanto, não pode sacrificar o poder crítico e emancipador dos direitos humanos, deformando-os e destituindo-os de sua função de salvaguardar a dignidade e a autonomia dos seres humanos, enquanto seres racionais, que pensam, agem e falam. Não se pode, pois, admitir um discurso intercultural que busque apenas "o denominador comum" de valores entre as diversas formas de vida socioculturais e que abra mão das reivindicações normativas dos direitos humanos, já que isso comprometeria a própria finalidade desses direitos e tornaria o diálogo sem sentido, uma vez que as culturas permaneceriam aferradas aos "seus valores", e cada cosmovisão permaneceria 
estanque e estática, o que, por si mesmo, já é um equívoco, pois, como bem aponta Bielefeldt (2000, p. 32), "a ideia de uma cultura voltada completamente para si mesma seria tão hipotética e abstrata como a de uma cultura mundial única ".

O discurso normativo intercultural então precisa respeitar as normas pragmático-transcendentais desde sempre contrafaticamente pressupostas por todos aqueles que argumentam, devendo as diversas formas de vida tentar se compreender, respeitando e entendendo as diferenças, mas se guiando apenas pela força do melhor argumento e buscando submeter suas propostas normativas ao crivo do princípio da universalização de tal sorte que aquilo que com ele não se coadune deva ser declarado inválido, ainda que se trate de uma peculiaridade cultural. Desse modo, concede-se racionalidade e legitimidade aos direitos humanos de modo que estes não sejam apontados como imposição da cultura ocidental.

\section{CONSIDERAÇÕES FINAIS}

A argumentação é uma atividade fundamental para o homem, pela qual este se relaciona com seus semelhantes para discutir e solucionar problemas, definir metas e realizar toda sorte de fins. Até mesmo o pensamento e a introspecção solitária, pela qual o ser humano tenta compreender a si e ao mundo e busca traçar seu próprio caminho existencial, repousam sobre a estrutura da argumentação pública. Não há, por conseguinte, como se subtrair ao discurso argumentativo - seja com os outros seja consigo mesmo - sob pena da autodestruição social e até psíquica.

A realização do discurso argumentativo, que, como visto, é inevitável, pressupõe, por sua vez, determinadas condições morais ideais, que, apesar de não serem observadas, muitas vezes são sempre antecipadas pelos participantes da argumentação e não podem ser negadas sem que se incorra em contradição consigo mesmo. Essas regras, que prescrevem a igualdade de direitos, o respeito e o reconhecimento recíprocos, a responsabilidade solidária pelos problemas comuns, a inclusão e a consideração dos interesses de todos, enquanto normas da argumentação racional, dirigem-se a toda a humanidade e conclamam todos à sua observância.

Desse modo, a partir das normas morais pressupostas em toda argumentação séria, pode-se justificar a realização de um discurso normativo intercultural racional que mantenha o poder emancipador e crítico dos direitos humanos e que respeite as diferenças e as peculiaridades de diferentes culturas, fundamentando, por conseguinte, a validade universal desses direitos. 


\section{REFERÊNCIAS}

ALEXY, Robert. Direito, Razão, Discurso. Tradução de Luís Afonso Heck. Porto Alegre: Livraria do Advogado, 2010.

APEL, Karl-Otto. The Response of Discourse Ethics. Leuven: Peeters, 2001.

. Transformação da Filosofia. Volume II. 2. ed. Tradução de Paulo Astor Soethe. São Paulo: Loyola, 2000.

BIELEFELDT, Heiner. Filosofia dos Direitos Humanos. Tradução de Dankwart Bernsmüller. São Leopoldo: Ed. UNISINOS, 2000.

CANÇADO TRINDADE, Antônio Augusto. Tratado de Direito Internacional dos Direitos Humanos. Volume I. Porto Alegre: Sergio Antonio Fabris Editor, 2003.

COSTA, Regenaldo da. Ética do Discurso e Verdade em Apel. Belo Horizonte: Del Rey, 2002.

HABERMAS, Jürgen. Comentários à Ética do Discurso. Tradução de Gilda Lopes Encarnação. Lisboa: Instituto Piaget, 1999.

. Consciência Moral e Agir Comunicativo. Tradução de Guido Antônio de Almeida. Rio de Janeiro: Tempo Brasileiro, 2003.

. Racionalidade e Comunicação. Tradução de Paulo Rodrigues. Lisboa: Edições 70, 2002.

. Verdade e Justificação. Tradução de Milton Camargo Mota. São Paulo: Edições Loyola, 2004.

OLIVEIRA, Manfredo. Sobre a fundamentação. Porto Alegre: Edpucrs, 1993.

PIOVESAN, Flávia. Direitos Humanos e Justiça internacional. São Paulo: Editora Saraiva, 2007. 


\section{FUNDAMENTAL ASPECTS OF UNIVERSAL HUMAN RIGHTS}

Abstract: Despite its enormous legal and philosophical importance, the idea of human rights still faces many challenges in the current world scene, not only with regard to their effectiveness, but primarily to their own justification before the entire international community. One of the main criticisms against human rights challenges their universal validity claim, asserting that such rights are nothing more than a veiled way of imposition of Western culture and values on other peoples. Against this relativistic stance, this work seeks to develop the transcendental-pragmatic argument of Karl-Otto Apel, whereby it intends to reveal the moral norms presupposed in any reasonable argument, in order to justify rationally the possibility of universal human rights and of a normative cultural discourse that can conciliate these rights with peculiarities of different cultures without sacrificing their power of critique and emancipation.

Keywords: Human Rights. Universalism. Transcendental Pragmatics.

Data de recebimento: jan/2011 - Data de aprovação: mar/2011 